\title{
Deep Bite Its Etiology, Diagnosis and Suchita Daokar and Management: A Review Gauri Agrawal
}

Csmss Dental College, Aurangabad, Maharashtra, India

\section{Abstract}

Deep bite is one of the most common malocclusion seen in children as well as adults and is most difficult to treat successfully. Unfavorable sequel of this malocclusion predisposes a patient to periodontal involvement, functional problems, and temporomandibular joint disturbance. Deep bite anteriorly could be caused by supraeruption of upper and/or lower incisors or infraeruption of posterior teeth. Methods of deep bite correction are extrusion of posterior teeth, intrusion of anterior teeth, combination of both, proclination of incisors and orthognathic surgical modality. This article will describe various appliances, their indication and contraindication and also with the biomechanics involved.

\section{Corresponding author: Gauri Agrawal}

\section{gauriagrawal405@gmail.com}

Csmss Dental College, Aurangabad, Maharashtra, India.

Tel: +91-9422917896

Citation: Daokar S, Agrawal G, Deep Bite Its Etiology, Diagnosis and Management: A Review. J Orthod Endod. 2016, 2:4.

\section{Introduction}

Deep bite is one of the most common malocclusion seen in children as well as adults and is most difficult to treat successfully. Bishara [1] (Glossary) defined Deepbite as Malocclusion in which the mandibular incisor crowns are excessively overlapped vertically by the maxillary incisors when the teeth are in centric occlusion.

Unfavorable sequel of this malocclusion predisposes a patient to periodontal involvement, abnormal function, improper mastication, excessive stresses, trauma, functional problems, bruxism, clenching and temporomandibular joint disturbance make geriatric dental service a losing battle unless overbite can be controlled.

\section{Classification}

Deep bite can be classified as dentoalveolar deep bite and skeletal deep bite, true deep bite and pseudo deep bite or incomplete deep bite and complete deep bite $[2,3]$.

\section{Etiology of deep bite}

The deep overbite may be caused by inherent or acquired factor [3]:

1) Inherent factors like Tooth morphology, Skeletal pattern and malocclusion, Condylar growth pattern.

2) Acquired factors like Muscular habit, Changes in tooth position, the loss of posterior supporting teeth, Lateral tongue thrust habit.

\section{Diagnosis of deep bite}

A deep bite anteriorly could be caused by supraeruption of upper and/or lower incisors or infraeruption of posterior teeth [4]. To evaluate whether infraeruption or supraeruption is present, the orthodontist must use linear measurements from the base of the alveolar process. This can be established by Cephalometric analysis.

\section{Treatment of overbite before overjet}

For stability in function and retention it is vital that the deep bite incisor relationship be corrected [5], to establish the proper interincisal relationship of overbite to overjet and inter-incisal angles.

\section{Treatment modalities of deep bite}

Methods of deep bite correction:

1) Extrusion of posterior teeth.

2) Intrusion of anterior teeth.

3) Combination of both.

4) Proclination of incisors.

5) Surgical.

\section{Extrusion of posterior teeth}

This modality of correction of deep bite is most commonly indicated in horizontal growing patients. The removable appliances such as bite planes, sved bite planes [3,6], modified 
bite planes, myofunctional appliances such as activator [7], Bionato [2], Functional regulator [8], Twin blocks [9] allow the extrusion of posterior teeth thus opening the bite. Cervical headgears exert a vertically downward component of force of about 200-300 g per side for duration of 14-16 h per day [10]. This creates potential for extrusion of the molars and the deep bite get corrected. Fixed modified Nance appliance, [11] fixed bite plate with glass ionomer cement [12] and bonded bite planes [13] with composite resin (indirect technique) on the palatal aspect of maxillary incisors also can be used for extrusion of posteriors.

\section{Intrusion of Anterior Teeth}

\section{Biomechanics of intrusion}

For intrusion of teeth the force should pass through centre of resistance so that translation motion takes place without any tipping. Further away the point of force of application from centre of resistance greater is the rotational moment. The possibility of flaring of incisors is more likely to occur specially in class II div 1 than class II div 2.

\section{Optimal intrusive force for anterior intrusion}

Optimal force range for intrusion has been a long time controversy. Many researchers [14] such as Reitan, Burstone, Bench, Gugino and Hilgers, Rickett, Liu and Herschleb, Nicolai, Kesling, Proffit, Siatkowski, Karanth and Shetty have suggested various optimal intrusive forces. However an unanimous decision is lacking. The force ranges on an average from 15-20 g for each upper incisor and 10-15 $\mathrm{g}$ for each lower incisor. In adults, the forces are to be applied carefully and somewhat towards a lower range [14].

\section{Correction of deep bite with begg's technique}

In Beggs technique there are Bite opening bends to activate arch wires so that they depress the upper and lower anterior teeth in their sockets in order to open up anterior deep bites $[15,16]$. In conventional Begg's technique the bite opening bends are given mesial to the molars. This may create a distal tipping of the molars. To overcome this difficulty, various authors have proposed different sites for bite opening bends in the arch wires [17-19].

\section{Correction of deep bite with edgewise}

For intrusion of a tooth, along with incisal positioning of the edgewise brackets, a bend is given in an archwire in such a way that the anterior segment of arch wire is made to lie gingivally to the bracket groove [20]. Use of continous archwire for opening the bite, has found to have deleterious effects on the anchorage units. Extra care is needed to prevent these side-effects [21].

Auxillary arch's such as utility arch, Burstone's 3 piece intrusion arch [22,23], Mulligan's intrusive arch [24], K-SIR arch [25], and CIA [26] are various different arches used along with preadjusted edgewise technique to bring about intrusion of the anterior teeth.

\section{Correction of deep bite with lingual orthodontic}

The distance in the sagittal plane between a lingual bracket and the $\mathrm{Cr}$ is much shorter than between a buccal bracket [27] and the $\mathrm{Cr}$ (Figure 1). Therefore, pure intrusion movement in LO (lingual orthodontic) will be closer to bodily movement than in Buccal Orthodontics (BO).

\section{Correction of deep bite with mini screw anchorage system}

To intrude the upper incisors, the best placement of mini-screw is between the upper lateral incisors and the canines [28]. The placement of the mini-screws should be done after levelling and alignment, in order to maximize the interradicular space at the placement site. In order to avoid tipping the upper incisors buccally during the intrusion, the end of the arch wire is cinched back.

\section{Correction of deep bite with magnets}

Magnets used in orthodontic are Samarium Cobalt (SmCo) magnets or aluminium-nickel-cobalt (AINiCo) magnets. Samarium cobalt magnets are used more over aluminium-nickel-cobalt for their superior properties [29]. They are used on buccal as well
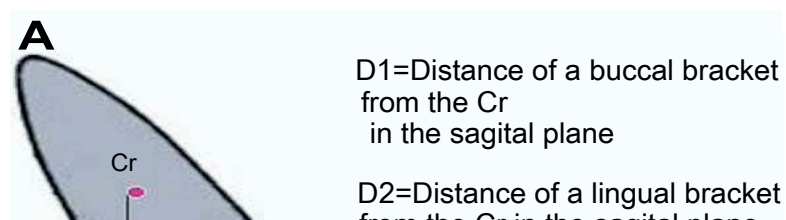
from the $\mathrm{Cr}$ in the sagital plane
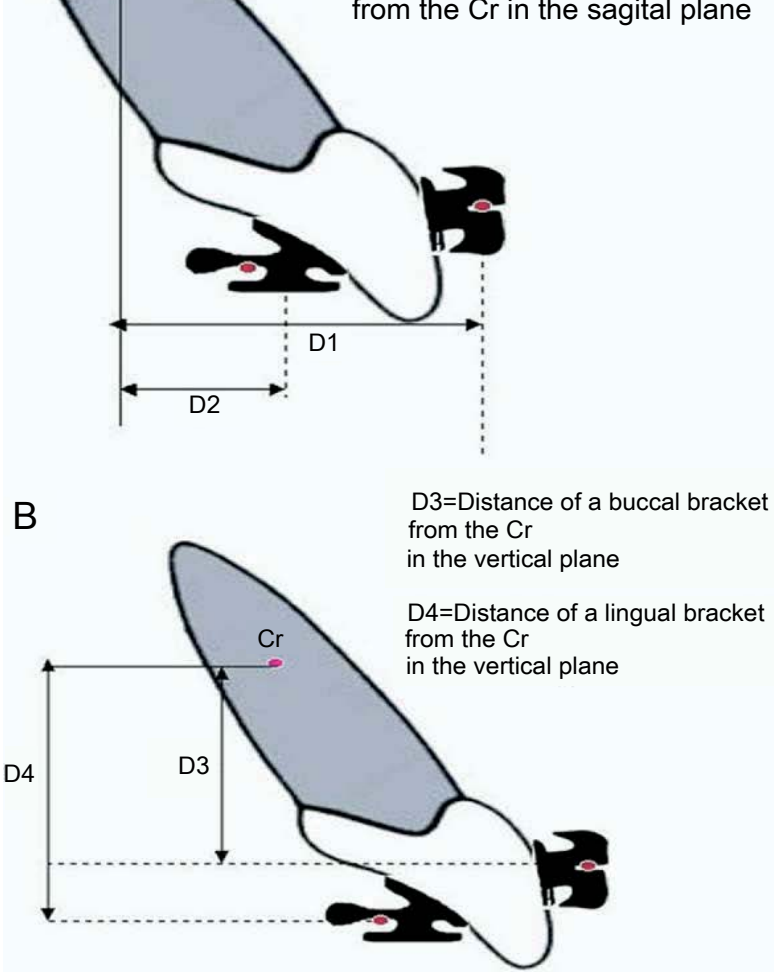

Figure 1 (A) Comparison between buccal and lingual brackets in the sagittal plane. (B) Comparison between buccal and lingual brackets in the vertical plane. 
as lingual or palatal side, but commonly used on buccal side in attractive mode. The force generated may average $120 \mathrm{~g}$, which may be controlled by operator by adjustment of the air gaps. Less air gaps between the magnets generate more force (Figure 2).

\section{Correction of deep bite with orthodontics and surgery}

An adult who has more than $6 \mathrm{~mm}$ overbite or $8 \mathrm{~mm}$ of overjet could be considered a candidate for surgery solely on the basis of dental relationships [30], without even considering facial esthetics.

The surgical treatment options in deep bite patients are [29]:

1) Orthodontics and interpositional genioplasty.

2) Orthodontics and Inferior onlay mandibuloplasty.

3) Orthodontics and mandibular advancement.

4) Orthodontics and total subapical mandibular advancement.

5) Orthodontics and inferior repositioning of maxilla and mandibular advancement.

6) Orthodontics and combined maxillary and mandibular surgery.

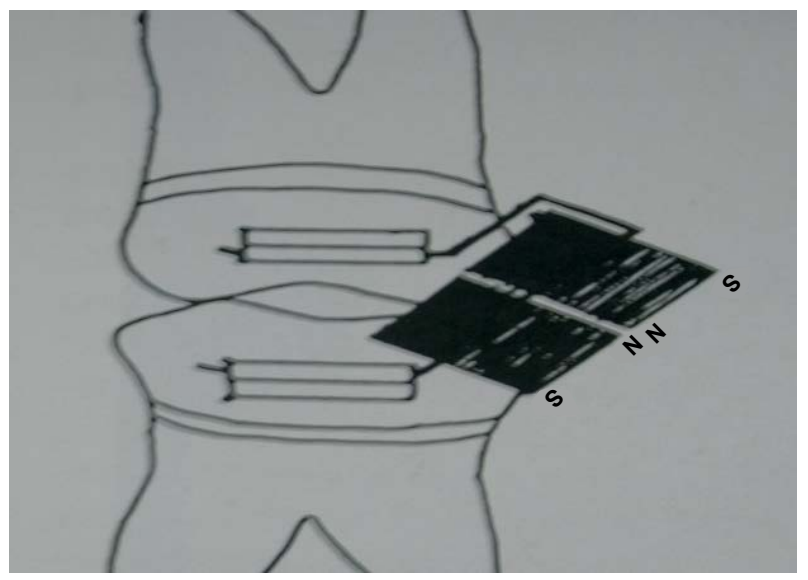

Figure 2 Attracting magnets for bite opening.

\section{Intrusion and apical root resorption}

Apical root resorption after intrusion depends to a large extent on the anatomical environment of the root. In young patients, apex is often surrounded by spongy bone and long marrow spaces. A light continuous force, such as that obtained in the light wire technique has proved to be favorable for intrusion of teeth in young patients. If the bone of the apical region is fairly compact, as it is in some adults, a light interrupted force may be preferable. If a definitely light force is exerted for a period of five to six weeks, there is less tendency to root resorption during the later period of intrusion [4,31,32].

\section{Summary and Conclusion}

Deep bite is a malocclusion that occurs in the vertical plane of space. Some degree of vertical overlapping or overbite is a normal feature of human dentition. However, some patients present with excessive overbite termed as deep bite or deep overbite. The deep bite in the permanent dentition may be caused by inherent factors or factors acquired during the life of that dentition.

A successful treatment of deep bite requires a careful analysis of the factors contributing the problems. During the treatment planning, considerations should be given to the soft tissue, skeletal pattern, stability, occlusal plane, interocclusal space, treatment time and age of the patient.

It is widely accepted that correction of deep bite is both easier to accomplish and more stable when it is performed on growing patients than when it is attempted on those with no appreciable growth remaining. Adults often need only correction of excessive overbite either due to its isolated nature or a demand for limited treatment. In adults, this treatment is often part of periodontal, restorative and/or temporomandibular joint therapy.

Deep overbite can be corrected by many ways like intrusion of anteriors, extrusion of posteriors, combination of anterior intrusion and posterior extrusion, proclinating anteriors or surgically. However, it should be decided which method will be more beneficial or which will improve the patients facial appearance and functional efficacy. 


\section{References}

1 Bishara (2002) S.E. Textbook of Orthodontics. Ed WB Saunders.

2 Graber TM, Rakosi T, Petrovic G (1985) Dentofacial Orthopedics with functional Appliances, St. Louis, Mosby Co.

3 Geiger A, Hirshfeld L (1974) Minor tooth movements in general practice ( $3^{\text {rd }}$ edn.), Mosby Co.

4 Graber TM, Vanarsdall R (1994) Orthodontics: Current Principles and Techniques ( $2^{\text {nd }}$ edn. $)$, St. Louis: Mosby Year Book.

5 Bench RW, Gugino CF, Hilgers JJ (1977) Biopragressive therapy Part2,7,10,11. J Clin Orthod 12: 192-521.

6 Walther DP (1966) Current Orthodontics eight Teachers. In: Bristol (ed.) John Wright and Sons Ltd.

7 Graber TM, Neuman B (1984) Removable orthodontic appliances (2 $2^{\text {nd }}$ edn.), W.B. Saunders Co. Philadelphia, USA.

8 Bhalaji SI (2015) Orthodontics: The art and science. Arya publishing house, New Delhi, India.

9 Clark WJ (1995) Twin block Functional therapy, application in dentofacial Orthopaedics. Mosby-Wolfe.

10 Toshniwal NG, Hazarey PV (1992) Extraoral orthodontic appliances. Library dissertation. Department of Orthodontics, G.D.C.H. Nagpur, India.

11 Northcutt ME (1995) The bite Plate Nance appliance. J Clin Orthod 29: $760-761$.

12 Jacksons, Sandler PJ (1996) Fixed bite planes for treatment of deep bite. J Clin Orthod 30: 283-287.

13 Philippe J (1996) Treatment of deep bite with bonded bite planes. J Clin Orthod 30: 396-400.

14 Divakar HS, Shetty S (2001) Comparative study of various intrusive arches. J Ind Orthod Soc 34: 82-91.

15 Begg PR, Kesling PC (1960) Begg Orthodontic therapy and technique ( $3^{\text {rd }}$ edn.), W.B. Saunders Co. Philadelphia, USA.

16 Jayade VP (1997) Refined Begg's for Modern Times (1 ${ }^{\text {st }}$ edn.). In: Jayade AV (ed.) Hubli, India.
17 Kameda A (1982) The begg technique in japan 1961-1979. Am J Orthod 81: 209-228.

18 Hocevar RA (1982) Orthodontic forces system: individualized treatment with open minded "begg" technique amj. Am J Orthod 81: 277-291.

19 Hocevar RA (1982) Orthodontic force system: technical refinement for increase efficiency. Am J Orthod 81: 1-11.

20 Renfroe EW (1975) Edgewise technique. Lea and Febiger Philadelphia.

21 Bennett J, McLaughlin R (1990) Management of deep bite with a preadjusted appliance system. J Clin Orthod 24: 684-696.

22 Shroff B, Yoon WM, Lindauer SJ, Burstone CJ (1997) Simultaneous intrusion and retraction using a three piece base arch Angle. Orthod 67: 455-461.

23 Shroff B, Lindauer SJ, Burstone CJ (1995) Segmented approach to simultaneous intrusion and space closure. Am J Orthod 107: 136-143.

24 Mulligan (1980) Common sense mechanics Part-12. J Clin Orthod 14: 546-553.

25 Kalra V (1998) Simultaneous intrusion and retraction of the Anterior teeth. J Clin Orthod 35: 535-540.

26 Nanda R, Marzban R, Kuhlberg A (1998) The connecticut Intrusion Arch. J Clin Orthod 35: 708-715.

27 Romano R (2006) Concepts on Control of the Anterior Teeth Using the Lingual Appliance. Semin Orthod 12: 178-185.

28 Carano A, Velo S, Incorvatic, Poggio P (2004) Mini - Screw - Anchorage - System in the maxillary alveolar bone. J Ind Orthod Soc 37: 74-84.

29 Blechman AM (1985) Magnetic force systems in orthodontics. Am J Orthod 87: 201-210.

30 Proffit WR, White RP (1990) Surgical orthodontic treatment. Mosby Co.

31 Wessberg GA, Fish LC, Epker BN (1982) The short face patient: Surgical orthodontic treatment options. J Clin Orthod 16: 668-685.

32 Graber TM (1996) Current orthodontic concepts and techniques. WB Sunders Co. 